\title{
EKOLOŠKE SLEDI KOT POMEMBEN ELEMENT GEOGRAFSKIH ZASNOV ZA PRIPRAVO LOKALNEGA PROGRAMA VARSTVA OKOLJA
}

\author{
mag. Roman Rozman
}

Trnovska vas $5 \mathrm{Ia}, \mathrm{SI}-2254$ Trnovska vas

e-mail:rozman_roman@yahoo.com

Izvirni znanstveni članek

COBISS 1.01

\section{Izvleček}

Lokalni programi varstva okolja so celoviti dokumenti, ki omogočajo lažje načrtovanje in reševanje okoljskih problemov. Ekološke sledi lahko predstavljajo pomemben del geografskih zasnov, ki lahko služijo za pripravo lokalnega programa varstva okolja. Izračun ekoloških sledi je na primeru občine Ormož pokazal, da trenutno občina ni na poti trajnostno sonaravnega razvoja, saj ekološke sledi presegajo sposobnosti bioproduktivne površine v občini. Ekološke sledi so znašale 4,3 gha/preb. (Slovenija - 3,4 gha/preb.), medtem ko je ekološki primanjkljaj 1,11 gha/preb. (Slovenija - 0,6 gha/preb.).

Ključne besede: varstvo okolja, ekološke sledi, občina Ormož, Podravje

\section{ECOLOGICAL FOOTPRINTS AS IMPORTANT ELEMENT OF GEOGRAPHICAL CONCEPTS FOR THE PREPARATION OF THE LOCAL ENVIRONMENTAL ACTION PLAN}

\begin{abstract}
Local environmental action plans are integral documents that enable more efficient planning and solving of environmental problems. Ecological footprints can represent the important part of geographical concepts for the preparation of the local environmental action plan. The calculation of ecological footprints has shown that at the moment, Ormož municipality does not follow the sustainable development. Municipality's ecological footprints exceed the capabilities of its bioproductive areas. Ecological footprints are 4.3 gha per inhabitant (Slovenia 3.4 gha per inhabitant), while the ecological deficit is 1.11 gha per inhabitant (Slovenia 0.6 gha per inhabitant).
\end{abstract}

Key words: environmental protection, ecological footprint, Ormož municipality, Podravje 


\section{UVOD}

Občina Ormož leži v severovzhodni Sloveniji, meri 141,6 km² in je imela leta 2002 12.738 prebivalcev v 61 naseljih. Severni del občine leži v Slovenskih goricah, južni del pa na Ptujskem polju. Občinsko središče je mesto Ormož, ki je imelo leta 20022210 prebivalcev oziroma $16,8 \%$ prebivalcev občine.

S pomočjo izračuna ekoloških sledi v občini Ormož smo dobili podobo dosedanje obremenjenosti okolja ter hkrati 'primernost' obremenjevanja okolja glede na sposobnosti okolja $\mathrm{v}$ določenih delih občine Ormož. Tovrsten podatek je pomemben element za postavitev geografskih zasnov za pripravo lokalnega programa varstva okolja (LPVO). Hkrati so ekološke sledi primeren kazalec intenzitete pritiskov prebivalcev na določenem območju.

\section{EKOLOŠKE SLEDI - METODOLOGIJA IN IZRAČUNI}

$\mathrm{Z}$ iskanjem in razvojem najprimernejše metode, ki bi pokazala oziroma izmerila, ali družba udejanja trajnostno sonaravni razvoj, se je ukvarjalo že veliko strokovnjakov. Pokazali bomo, da je metoda ekoloških sledi primerna metoda merjenja trajnostno sonaravnega razvoja. Hkrati bomo s pomočjo ekoloških sledi analizirali pritiske na okolje, saj so ekološke sledi sintezni kazalec pritiskov na okolje.

V slovenski literaturi se za poimenovanje 'ecological footprint' uporabljata dve pojmovanji: okoljski odtis (Vendramin 2005; Vintar Mally 2006) in ekološke sledi (Žun 2004). Mi bomo uporabljali izraz ekološke sledi, saj se nam zdi poimenovanje primernejše.

Kazalec ekoloških sledi, ki meri obremenjenost in pritiske družbe na okolje, je po našem mnenju primeren, saj vsebuje številne pozitivne lastnosti, ki naj bi jih izpolnjevali ustrezni kazalci.

\section{I Metodologija izračunov ekoloških sledi}

Ker se življenjski prostor ne izkorišča enakomerno, so v zadnjem desetletju nastali številni poskusi merjenja 'prisvojitve okoljskega prostora'. Metoda merjenja velikosti 'prisvojenega prostora' se imenuje ekološke sledi (ang. ecological footprints). To metodo merjenja so razvili na univerzi British Columbia v Kanadi leta 1996 pod vodstvom Williama Reesa in Mathisa Wackernagla (Our ecological footprint 1996). Po drugih virih pa naj bi teorijo oziroma metodo merjenja sonaravno trajnostnega razvoja razvili že leta 1992 v okviru projekta Sustainable Europe (Listina evropskih mest in velemest 2004). Veliko je k razvoju metode prispevalo delovanje institucij in organizacij Redefining Progress (Oakland, ZDA), Global Footprint Network (Oakland, ZDA) in World Wildlife Federation International (WWF International) (Gland, Švica) z vsakoletnimi poročili WWF International (Living planet report) ter številnimi prispevki Mathisa Wackernagla, Chada Monfrede, Dana Morana, Stevea Goldfingerja in drugih.

Ekološke sledi predstavljajo površino prostora, ki je potrebna za stalno proizvodnjo in asimilacijo odpadkov ter snovi, ki jih proizvede opazovani sistem. Metoda se osredotoča predvsem na tiste človeške aktivnosti, ki vplivajo na podporne storitve narave. Metodologija 
se razvija že več kot 15 let, a kljub temu še vedno vsebuje pomanjkljivosti, ki jih bo treba v prihodnje odpraviti (Wackernagel in sod. 2005). Metoda je bila v preteklih letih uporabljena pretežno v globalnem merilu predvsem zaradi tega, ker so ekološke sledi integralni kazalci uravnoteženega razvoja. Merjene so s ploskovnimi enotami in so kot absolutne vrednosti zelo nazorne ter jih je lahko primerjati. Na lokalnih območjih je bila uporaba dokaj redka, v zadnjih letih so jo uporabili za večja mesta.

Ekološke sledi so idealen kazalec merjenja šibke ali močne sonaravnosti. Vladi oziroma voditeljem lokalne skupnosti omogočajo spoznati, kako uravnavati nadaljnji razvoj (monitoring), in sicer (Wackernagel in sod. 2006, 111):

- vzpostavitev monitoringa merjenja ekoloških sledi in poskus vzpostavitve odgovornosti gospodarstva za izmerjene rezultate;

- poskusi prilagajanja gospodarstva sonaravnim smernicam za zmanjšanje primanjkljaja;

- $\quad$ vključitev oziroma boljša izkoriščenost dosedanjega premoženjskega stanja v nadaljnje planiranje;

- omogočanje zgodnejšega opozarjanja in varnosti na dolgi rok;

- opozarjanje na vse ekološke pritiske (tipične), ki so neodvisni (klimatske spremembe, uničenje kmetijskih zemljišč);

- identificiranje lokalnih in globalnih možnosti za ublažitev (na primer klimatskih sprememb);

- vplivanje političnih odločitev na posledično prihodnje boljše priložnosti in možnosti za razvoj (skladi denarja za ta namen, sonaravni razvoj naselij ...).

Metoda temelji na nosilni kapaciteti okolja, ki omogoča primerjavo v denarju, kljub temu da se ekološke sledi merijo v globalnih hektarjih (slika 1). Ekološke sledi se letno izračunajo za več kot 150 držav. Za manjša območja (predvsem večja mesta) so potrebne individualne študije. Ekološke sledi so odlično orodje za strategije in načrtovanje (Wackernagel in sod. 2006, 104).

Slika 1: Globalni hektar v razmerju do sveta

Figure 1: Global hectar in relation to the world

1 gha $=1$ ha biološko produktivnega prostora povprečne svetovne produktivnosti

Vir: City limits 2002, 45.

Metoda temelji na nosilni kapaciteti okolja, ki pomeni zmogljivost narave, da prenese določeno stopnjo človekove obremenitve, ki v naravi ne povzročijo sprememb kakovosti in ne porušijo ravnovesja (Lah 2002). Ključni cilj ekoloških sledi je primerjava z aktualnimi bioproduktivnimi površinami v opazovanem sistemu.

Ekološke sledi je mogoče določiti $\mathrm{z}$ vrednotenjem snovnih in energijskih tokov $\mathrm{v}$ opazovanem sistemu (slika 2):

- integralna (sestavljena) metoda ('compound method') - ovrednotijo se vstopajoči notranji viri in izstopajoči tokovi. Tovrstna metoda je primerna za dobro obdelana statistična območja, npr. za Slovenijo (Medved 2006); 
- komponentna metoda ('component-based method') -ovrednotijo se potrebe posameznikov v sistemu, vsota ekoloških stopinj vseh posameznikov predstavlja ekološke stopinje opazovanega sistema. Podatek se ekstrapolira na vse prebivalce območja. Metoda je znana pod imenom The EcoIndexTM Methodology in je bila razvita predvsem za večja mesta (na primer London), regije in občine (The footprint of Wales 2002).

V začetku je bila $\mathrm{v}$ uporabi zgolj komponentna metoda. Ta ima nekaj pomanjkljivosti: rezultat je odvisen od kvalitete vhodnih podatkov, težave $\mathrm{z}$ mejami, problem dvojnega štetja v kompleksnih sistemih (The footprint of Wales 2002). Nasprotno uporaba integralne metode temelji zgolj na nacionalnih podatkih. V zadnjem času prevladuje uporaba integralne metode (Wackernagel in sod. 2005). Problem integralne metode (podobno kot pri komponentni) je prav tako dvojno štetje (predvsem na področjih, kjer je vključena energija). Mnogo lažje so merljivi energijski tokovi kot pa snovni (Medved 2006).

Pri komponentni metodi, ki smo jo uporabili za občino Ormož, govorimo o metodi oziroma načinu obdelave od spodaj navzgor. Tudi pri tej metodi so uporabljeni vsi podatki, če je le možno. Številne komponente, na primer energija, so sestavljene iz mnogih manjših kategorij (komponent), na primer elektrika, plin ... Pri komponentni metodi se dvojnemu štetju poskušamo izogniti s pomočjo prilagoditve in izločitvijo komponent (The footprint of Wales 2002), ki bi dovolile morebitno dvojno štetje (City limits 2002, 40).

Izračun ekoloških sledi temelji na naslednjih predpostavkah (Žun 2004; Wackernagel in sod. 2005; Living planet report 2005):

- $\quad \mathrm{v}$ določenem sistemu je mogoče slediti snovnim in energijskim tokovom (podatki se zbirajo v državnih in mednarodnih organizacijah), vključno s količinami odpadkov, ki pri porabi in pretvorbah nastajajo;

- za večino surovin in odpadkov, ki pri njihovi uporabi nastanejo, lahko njihove količine ob upoštevanju tehnologij črpanja, uporabe in odlaganja izrazimo s površino prostora, ki je potrebna, da so ti tokovi stalni;

- $\quad$ vodilno pravilo metode je, da upošteva največje znane vplive okolja;

- $\quad$ surovin, za katere ne moremo določiti toka porabe in odpadkov, ne vključujemo v izračun ekoloških sledi;

- $\quad$ v primeru dvomov izberemo najbolj previdno oceno ekoloških sledi, to je tisto, ki nam da največjo vrednost;

- $\quad$ pri izračunu ekoloških sledi ne upoštevamo aktivnosti ljudi, za katere trenutno ni zadovoljivih podatkov;

- $\quad$ pri analizah ne upoštevamo aktivnosti, ki nepopravljivo uničujejo okolje (izsuševanje vodonosnikov, golosek ... ), ali rabe snovi, ki se v okolju ne razgradijo (plutonij, CFC).

Pri komponentni metodi se izračuna poraba posamezne dobrine (energentov in snovi) na prebivalca. Podatek pomnožimo z utežnim faktorjem, ki ga najdemo s pomočjo literature (Chambers, Simmons, Wackernagel 2000; Wackernagel, Rees 1996). Ekološke sledi porazdelimo na šest različnih tipov bioproduktivnih površin prostora in sedem glavnih snovnih ter energijskih tokov. 


$$
E S=\sum_{l=1}^{n} \sum_{j=1}^{6} k_{j, l} r_{j, l}
$$

kjer je:

$l$ - vrsta energenta ali snovi,

$j$ - vrsta bioproduktivne površine,

$r$ - raba posamezne dobrine (GWh/leto na preb. ali t/leto na preb.),

$k_{i, l}$ - pretvorbeni faktor za posamezno dobrino, razdeljeno po tipih bioproduktivne površine

Slika 2: Površine, potrebne za izračun ekoloških sledi

Figure 2: Areas, needed to calculate ecological footprints

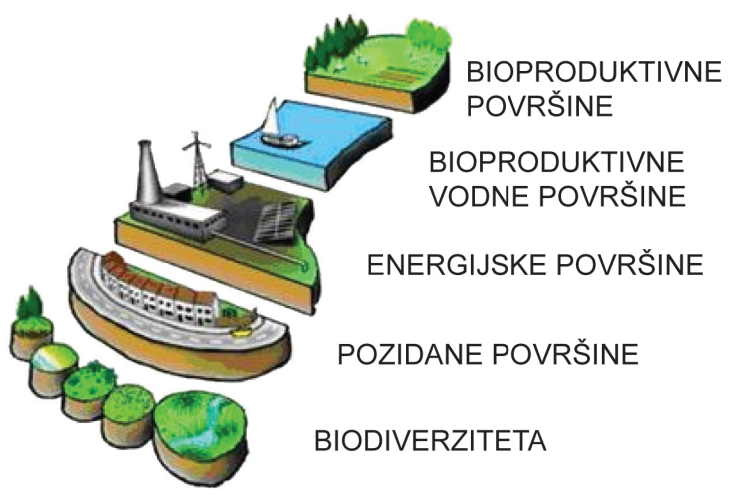

Vir: prirejeno po City limits 2002.

Prostorska primerjava med posameznimi območji znotraj občine Ormož praktično ni mogoča, saj so podatki za majhna območja, kakršna je občina Ormož, težko dostopni. Računanje ekoloških sledi je najprimernejše za območja, ki so velika kot regija ali država. Problemi so predvsem zaradi nedostopnih podatkov, saj je s tem onemogočen izračun ekološki sledi in biološke kapacitete.

Podatke, ki so potrebni za izračun (poraba električne energije idr.), smo pridobili iz podatkov različnih javnih in zasebnih podjetij, ki opravljajo raznovrstno dejavnost ter podatkov iz Statističnih letopisov (SURS), saj vsi podatki niso bili dostopni v podjetjih. Te smo kot povprečja prenesli na občana občine Ormož (napaka, ki se pojavi zaradi tega, je manjša od $5 \%$ ). Poudariti moramo, da se pridobljeni podatki o letni porabi nanašajo na območje nekdanje občine Ormož, sedanjih treh občin (Ormož, Središče ob Dravi in Sveti Tomaž), kar pa nenazadnje sploh ni tako napačno, saj je napaka po našem mnenju zanemarljiva. Podatki na občana občine Ormož so podani na osnovi števila prebivalcev sedanje občine Ormož $(74,5 \%)$. 
Večina podatkov je iz leta 2006, nekateri so tudi iz leta 2002, ker novejši podatki niso bili dostopni. Ekološke sledi na koncu vedno zaokrožimo na 2 decimalki. Če je sled manjša od 0,05 , je vrednost enaka 0 . Takšna so priporočila strokovnjakov za metode ekoloških sledi.

Skupni seštevek ekoloških sledi za leto 2006 znaša 4,30 gha na prebivalca občine Ormož (preglednica 1). Kljub računanju povprečij iz slovenskih podatkov (vir: SURS) na občana občine Ormož zaradi nedostopnosti nekaterih podatkov lahko trdimo, da zaradi tega napaka izračuna ni večja od $5 \%$. Za Slovenijo znašajo ekološke sledi 3,8 gha/preb. za leto 2001 (Living planet report 2005) in 3,4 gha/preb. za leto 2003 (Living planet report 2006). Podatek za občino Ormož je višji predvsem zaradi večje porabe energije, skromne uporabe javnega prevoza in še vedno nezadostne reciklaže odpadkov.

Preglednica 1: Ekološke sledi, preračunane na prebivalca občine Ormož v letu 2006 Table 1: Ecological footprint per inhabitant of Ormož municipality in 2006

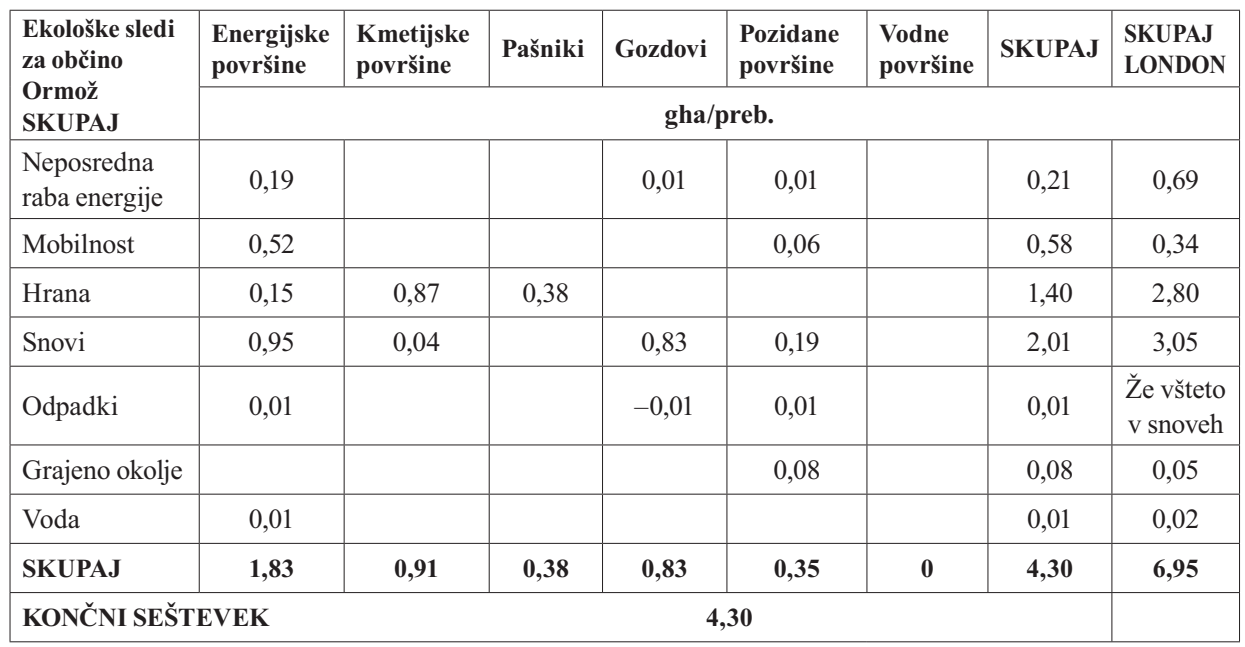

Slika 3: Ekološke sledi prebivalcev občine Ormož v letu 2006

Figure 3: Ecological footprint of inhabitants of Ormož municipality in 2006

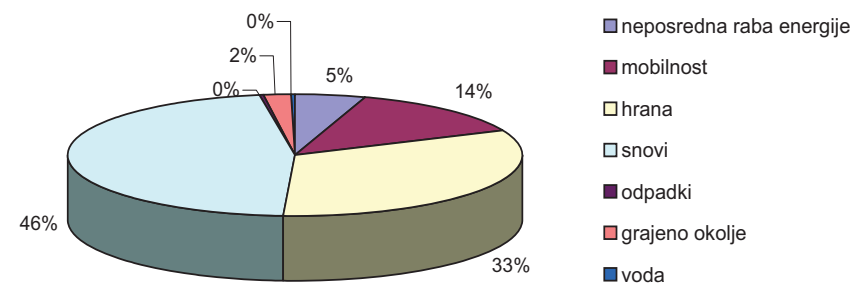


Žun (2004) je s podobno metodologijo izračunal ekološke sledi prebivalcev občine Naklo, in sicer 4,57 gha/preb. V občini Ormož so ekološke sledi nižje. Še veliko slabše kot v občini Ormož je trajnostno sonaravni razvoj naravnan v mestu London, kjer ekološke sledi znašajo kar 6,95 gha/preb., medtem ko znaša bioproduktivna površina zgolj 0,16 gha/prebivalca, svetovna pa $1,78 \mathrm{ga} / \mathrm{preb}$. (City limits 2002).

Ekološke sledi po področjih kažejo, da imajo največjo težo pri ekoloških sledeh v občini Ormož hrana, snovi in mobilnost (slika 3). Zanimiv je nizek delež rabe energije; velik delež ekoloških sledi se kot posledica rabe energije skriva tudi pod rabo in oskrbo prebivalcev $\mathrm{s}$ hrano in snovmi. Posebej problematična je raba snovi in hrane, ki predstavljata $80 \%$ ekoloških sledi.

\subsection{Opredelitev in izračun bioproduktivih površin}

Bioproduktivna površina je za izračun ekoloških sledi zelo pomembna. Primerjava ekoloških sledi in bioproduktivne površine nam pove, kako je populacija na nekem območju presegla ali še ni dosegla praga sonaravno trajnostnega razvoja oziroma zmogljivosti okolja. Bioproduktivne površine se med seboj precej razlikujejo po količini proizvedenih snovi ter po sposobnosti asimilacije odpadkov in drugih snovi.

Za izračun potrebnih ekoloških sledi je bioproduktivna površina razdeljena na 4 osnovne tipe (preglednica 2): bioproduktivne površine, bioproduktivne vodne površine, energijske površine in pozidane površine. Peti tip površin predstavlja biodiverziteto oziroma površino, ki je potrebna za njeno ohranitev (City limits 2002, 45). Biodiverziteta je sestavljena iz vseh živih organizmov, zemeljskih, morskih in ostalih morskih ekosistemov ter ekoloških kompleksov (Kooten in Bulte 2000).

Preglednica 2: Vrste bioproduktivnih površin

Table 2: Types of bioproductive areas

\begin{tabular}{|c|l|}
\hline Zap. št. $=\mathbf{j}$ & VRSTE BIOPRODUKTIVNIH POVRŠIN \\
\hline 1 & Kmetijske površine \\
\hline 2 & Pašniki \\
\hline 3 & Gozdovi \\
\hline 4 & Sladko- in slanovodne površine za ribištvo \\
\hline 5 & Pozidane površine (naselja, prometne poti, infrastrukturne površine) \\
\hline 6 & Energijske površine kot ponor toplogrednih plinov, izraženih s $\mathrm{CO}_{2}$ ekvivalentom \\
\hline
\end{tabular}

Vira: Šašek-Divjak 1997; Wackernagel in Rees 1996.

Za določitev bioproduktivnih površin je treba opredeliti nekaj pojmov: ekvivalentni faktor, globalni hektarji in faktor pridelka. Zaradi lažje primerljivosti v globalnem smislu je treba bioproduktivne površine modificirati s tako imenovanim ekvivalentnim faktorjem (to je povprečna svetovna produktivnost), ki nam kasneje prinesejo ekvivalentne površine. Slednje so merljive v globalnih hektarjih (ang. global hectars) (Wackernagel in Rees 1996). 
Vsak globalni hektar predstavlja enako vsoto biološke produktivnosti. Seštevek globalnih hektarov (različnih bioproduktivnih površin) in seštevek navadnih hektarjev predstavlja enako površino. To dejstvo omogoča popolno primerljivost, ne glede na to, kje na svetu se neka površina nahaja.

Ker se absorpcijska sposobnost in rodovitnost površin geografsko razlikujeta, je treba sistem ovrednotiti še s faktorjem pridelka (ang. yield factor). Na bioproduktivno površino vpliva tudi velikost populacije, zato je ekvivalentna bioproduktivna površina izračunana na prebivalca oziroma posameznika, ki se obravnava v določenem prostoru. Pri pozidanih površinah je treba upoštevati, da je med njimi 10 \% zelenih površin (Šašek-Divjak 1997; Wackernagel in Rees 1996; Wackernagel in sod. 2005). Ker populacija ne sme površine v celoti uničiti oziroma je zasesti, saj sta $v$ tem primeru ogroženi regeneracijska sposobnost in biotska raznovrstnost, je treba odšteti površino za ohranjanje biotske raznovrstnosti. Deleži površine za ohranjanje biotske raznovrstnosti so zelo različni - od 3,5 do $50 \%$, vendar je najpogostejši (najmanjši še sprejemljiv) delež $12 \%$, ki smo ga upoštevali tudi v naših izračunih (Our common future 1987).

Faktorji pridelka so za Slovenijo (tudi občino Ormož) določeni na osnovi količin pridelka in glede na svetovno povprečje (Statistični letopis 2002; Matijašič 2003). Postopek izračuna bioproduktivne površine za občino Ormož in Slovenijo je enak (preglednica 3).

Preglednica 3: Velikost bioproduktivnih površin v občini Ormož za leto 2006

Table 3: Size of bioproductive areas in Ormož municipality for year 2006

\begin{tabular}{|l|c|c|c|c|c|}
\hline $\begin{array}{l}\text { VRSTA } \\
\text { BIOPRODUKTIVNIH } \\
\text { POVRŠIN }\end{array}$ & Površina (ha) & $\begin{array}{c}\text { Površina na } \\
\text { prebivalca } \\
\text { (ha/preb.) }\end{array}$ & $\begin{array}{c}\text { Ekvivalentni } \\
\text { faktor } \\
\text { (gha/ha) }\end{array}$ & $\begin{array}{c}\text { Faktor } \\
\text { pridelka }\end{array}$ & $\begin{array}{c}\text { Bioproduktivne } \\
\text { površine } \\
\text { (gha/preb.) }\end{array}$ \\
\hline $\begin{array}{l}\text { Rodovitne kmetijske } \\
\text { površine }\end{array}$ & 8780,0 & 0,69 & 2,11 & 1,69 & 2,46 \\
\hline Pašniki & 957,3 & 0,08 & 0,47 & 3,60 & 0,13 \\
\hline Gozd & 3735,1 & 0,29 & 1,35 & 2,42 & 0,96 \\
\hline $\begin{array}{l}\text { Sladko- in slanovodne } \\
\text { površine kot vir hrane }\end{array}$ & 0,0 & 0,00 & 0,35 & 1,00 & 0,00 \\
\hline Pozidane površine naselij & 695,0 & 0,06 & 1,35 & 1,00 & 0,08 \\
\hline SKUPAJ & $14.167,4$ & 1,12 & & & 3,62 \\
\hline $\begin{array}{l}\text { POTREBNO ZA BIOTSKO } \\
\text { RAZNOVRSTNOST } \\
(12 \% \text { POVRŠIN) }\end{array}$ & 1700,09 & 0,13 & & & 0,43 \\
\hline $\begin{array}{l}\text { SKUPAJ (S POTREBNO } \\
\text { POVRŠINO ZA BIOTSKO } \\
\text { RAZNOVRSTNOST) }\end{array}$ & & & & & 3,19 \\
\hline
\end{tabular}

Bioproduktivnih površin je v občini Ormož 3,19 gha na prebivalca. To je več kot znaša izračunana vrednost za Slovenijo za leto 2001 (2,9 gha/preb.; Living planet report 2005) ali za leto 2003 (2,8 gha/preb.; Living planet report 2006). V občini Ormož je ta vrednost za 12,2 \% višja v primerjavi s podatki za Slovenijo (2003) in za 44,2 \% višja glede na svetovno 
povprečje (1,78 gha/preb.). Žun (2004) je za občino Naklo (4847 preb., 28,3 km²) po enaki metodologiji izračunal za 50 \% nižjo vrednost bioproduktivnih površin, vendar ima ta občina manj rodovitnih kmetijskih površin kot ormoška.

\subsection{Oznaka in izračun ekološkega presežka/primanjkljaja}

Ekološke sledi populacije so lahko v nekem prostoru večje ali manjše od bioproduktivnih površin. Če so ekološke sledi večje od bioproduktivnih površin, govorimo o ekološkem primanjkljaju, v nasprotnem primeru pa o ekološkem presežku. V primeru primanjkljaja populacija $\mathrm{v}$ danem prostoru prekomerno izkorišča potenciale svojega okolja. Razvoj v tem primeru ni uravnotežen.

\section{Ekološki presežek/primanjkljaj = ekološke sledi (gha) - bioproduktivnost (gha)}

Ekološka uravnoteženost pokaže, ali je neka skupnost na poti trajnostno sonaravnega razvoja. Ekološka uravnoteženost občine Ormož je negativna in znaša $-1,11$ gha/preb. (preglednica 4). V primeru občine Ormož govorimo o ekološkem primanjkljaju, ki je posledica visokih pritiskov (ekoloških sledi). Za Slovenijo je ekološki primanjkljaj znašal v letu $2001-0,9$ gha/preb. (Living planet report 2005) in v letu $2003-0,6$ gha/preb. (Living planet report 2006). Razlika med občino Ormož in slovensko ekološko uravnoteženostjo je $0,21 \mathrm{gha} /$ preb. (2001) in 0,51 gha/preb. (2003) v prid Sloveniji. Pri Sloveniji je uporabljena integralna, pri občini Ormož pa komponentna metoda računanja ekoloških sledi, vendar obe metodi uporabljata enotno metodologijo računanja, saj gre za vrednotenje snovnih in energijskih tokov.

Primanjkljaj ekološke uravnoteženosti je v občini Ormož torej za 54 \% višji v primerjavi s podatkom, ki velja za povprečnega Slovenca (ekološki primanjkljaj 0,6 gha/preb.). Kljub temu da ima občina Ormož višjo bioproduktivno površino, je primanjkljaj občine Ormož večji. Velika je razlika med energijskimi površinami (1,83 gha/preb.) in gozdovi ( $0,83 \mathrm{gha} /$ preb.) ter znaša 1 gha/preb. Razlika je lahko pomembna predvsem zaradi uvajanja taks (kuponov) na emisije toplogrednih plinov. $\mathrm{V}$ tem primeru velja le površina gozda, teh pa je v občini Ormož za približno polovico manj (29 \%) kot v vsej Sloveniji (63,5 \%; Zavod za gozdove Slovenije, ustni vir). Rodovitne kmetijske površine pa na višino taks najbrž ne bodo vplivale.

Obstaja veliko načinov, kako zmanjšati ekološke sledi. Ker je največ (približno 80 \%) pritiskov (ekoloških sledi) povzročenih zaradi preveč porabljene energije (fosilnih goriv), hrane in snovi, je potrebno iz tega razloga posvetiti več pozornosti zmanjševanju tovrstnih pritiskov. S pomočjo nekaj manjših ukrepov je mogoče zelo znižati emisije in s tem zmanjšati onesnaževanje okolja. Velika prednost ekoloških sledi je tudi sposobnost napovedovanja (scenarijev) prihodnjega razvoja na podlagi projekcij.

Občina Ormož bo lahko v veliki meri vplivala na zmanjšanje pritiskov (ekoloških sledi), če bo sledila naslednjim zahtevam:

- spodbujala recikliranja odpadkov;

- razvijala javni prevozni sistem; 
- imela veliko kolesarskih stez;

- spodbujala gradnjo okolju prijaznih stavb s čim manjšo porabo energije;

- spodbujala podjetništvo, ki bo uporabljalo okolju prijazne materiale, tehnologije in proizvajalo okolju prijazne produkte (tako imenovani zeleni poklici);

- spodbujala porabo okolju prijaznih produktov.

Vsak povprečen prebivalec občine Ormož uporablja 1,34-krat (134 \%) povprečne zemeljske površine. Če bi vsi prebivalci sveta živeli in porabili toliko dobrin kot povprečen prebivalec občine Ormož, bi potrebovali dodatne 0,34 (1/3) Zemlje za podporo globalne potrošnje.

Trenutno življenje občanov občine Ormož ni na poti trajnostno sonaravnega razvoja (preglednica 4). Če primerjamo ekološko potrebo občanov občine Ormož $\left(547,73 \mathrm{gkm}^{2}\right) \mathrm{z}$ geografsko velikostjo občine Ormož $\left(141,6 \mathrm{~km}^{2}\right)$, potem so sledi občanov 3,8-krat večje od velikosti domače občine. Ekološke sledi $\left(547,73 \mathrm{gkm}^{2}\right)$ občanov občine Ormož so $1,34-$ krat večje od ormoških lokalnih bioproduktvnih površin $\left(406,36 \mathrm{gkm}^{2}\right)$. Vsak povprečen občan ormoške občine uporablja 1,34-krat (134 \%) povprečne zemeljske površine. Če bi vsi prebivalci sveta živeli in porabili toliko dobrin kot povprečen občan občine Ormož, bi potrebovali dodatne $0,34(1 / 3)$ Zemlje za podporo globalne potrošnje.

Preglednica 4: Prikaz neuravnoteženosti razvoja s pomočjo izračunanih ekoloških sledi v občini Ormož

Table 4: Review of unequilibration development with calculated ecological footprint in Ormož municipality

\begin{tabular}{|l|c|}
\hline VRSTA POVRŠINE & Površina/število \\
\hline Ekološke sledi $\left(\mathrm{gkm}^{2 *}\right) 4,3 \mathrm{gha} / \mathrm{preb}$. & 547,73 \\
\hline Bioproduktiva površina občine $\left(\mathrm{gkm}^{2}\right) 3,19$ gha/preb. & 406,34 \\
\hline Razlika - primanjkljaj $\left(\mathrm{gkm}^{2}\right) 1,11 \mathrm{gha} / \mathrm{preb}$. & 141,39 \\
\hline Površina občine $\left(\mathrm{km}^{2}\right)$ & 141,6 \\
\hline Število dodatnih potrebnih površin občin (planetov)** & $34 \%$ \\
\hline
\end{tabular}

* gkm² pomeni globalni kvadratni kilometer (pretvorba enote iz globalnega hektarja zaradi preglednejšega prikaza).

** Število dodatnih potrebnih površin občine ob sedanjem načinu življenja.

\subsection{Kritika metode ekoloških sledi}

Kvalitetna metoda lahko prinese dobre rezultate le ob upoštevanju navodil in standardov. Ko se je metoda ekoloških sledi še razvijala, se je dogajalo, da je veliko raziskovalcev in znanstvenikov po svoje definiralo kazalce in kriterije, ki morajo biti upoštevani v izračunu. Metoda se je do danes razvila do te mere, da teži k uporabi standardov in normativov, tako da so lahko izračuni primerljivi po vsem svetu. Ob upoštevanju teh standardov je možno dobiti kvalitetne in predvsem primerljive podatke. S standardi dosežemo, da so analize transparentnejše, zanesljivejše in jim lahko bolj verjamemo (Ecological footprint standards 2006). 
S tem se zagotovi primerljivost in zadovoljiva kvaliteta izračuna. Zagotavlja se tudi boljša medkrajevna in časovna primerljivost. Obstajata dve glavni vrsti standardov: uporabnostni standardi (namenjeni izračunu ekoloških sledi) in standardi sporočanja (namenjeni zahtevam interpretacije rezultatov ekoloških sledi).

Metoda ekološkega sledenja populacije je prav gotovo dobra metoda, saj omogoča primerjanje, kako je razvoj populacije na določenem območju trajnostno sonaravno naravnan v primerjavi z bioproduktivno površino območja.

Najslabše je, če so vhodni podatki napačni in je do napake prišlo že pri pridobitvi podatkov. Wackernagel in sod. (2005) sodijo, da so izračunane ekološke sledi v veliko primerih precenjene ali podcenjene. Velikokrat se je zgodilo, da je bila bioproduktivnost precenjena, ekološke sledi pa podcenjene in prenizke. Podobna napaka se je lahko zgodila tudi v našem primeru.

Napake (pomanjkljivosti) in prednosti metode so naslednje:

- unikatna in močno shematska metoda ter izobraževalno orodje (Capelis in sod. 2000);

- nekateri negativni vplivi in procesi v izračunu niso všteti (npr. erozija prsti, zastrupljanje podtalnice, kisli dež), kar vodi v nižji izračun ekoloških sledi;

- izključene so aktivnosti, ki sistematično uničujejo naravno nosilnost in njeno regeneracijo (npr. plutonij v biosferi, dioksini, CFC, krčenje gozda, širjenje puščav);

- globalni trg in turizem lahko veliko bolj vplivata na neko območje kot drugod, ob sorazmerno enakih pritiskih, kar lahko metoda prezre;

- napake podatkov in izračunov, majhen delež napak je skorajda nemogoče odkriti, vendar je njihov delež v skupnem seštevku zanemarljiv (majhen);

- komponentna metoda je manj kritična do potrošništva;

- ekološke sledi je možno izračunati na vseh ravneh (od osebne - lokalne do globalne ravni, (Capelis in sod. 2000);

- odlično analitično orodje za primerjave (Capelis in sod. 2000);

- računanje manjkajočih podatkov iz povprečij (iz globalne sfere na nacionalno in iz nacionalne na lokalno raven) privede do napak zaradi prenosa podatkov na nižjo raven. Wackernagel in sod. (2005) ocenjujejo, da omenjena pomanjkljivost prinese manj kot $5 \%$ napake v skupnem izračunu ekoloških sledi (podobno bi veljalo tudi za naše preračunavanje podatkov občini Ormož);

- metoda potrebuje podatke za določeno leto; če teh podatkov ni, je možno podatek pridobiti na dva načina: izračuni povprečja iz višje hierarhične prostorske ravni (sveta, države) ali izračunanje časovnega trenda. Omenjena rešitev nima velikega vpliva na končni rezultat;

- na svetovni (državni) ravni se pojavi težava zaradi neprimerljivosti zbranih podatkov različnih institucij;

- $\quad$ ekološki izračuni se uporabljajo v različnih jezikih, izračuni so kompleksni in zahtevni;

- težko sledenje številnim podatkom;

- $\quad$ vsi podatki zaradi kompleksnosti kljub velikemu številu verjetno še vedno niso zajeti;

- veliko je predpostavk in generalizacij;

- problem globalnih hektarjev, saj je na primer energija veliko bolj abstraktna, da bi jo lahko izrazili kot površino; 
- težko je doumeti, da pri oceni lahko govorimo o pretirani porabi (potrošništvu) in so izračunane ekološke sledi predstavljive (Capelis in sod. 2000);

- preveč črnoglede in krivične ocene (Capelis in sod. 2000);

- izmerjene vrednosti se preveč odzivajo na majhne spremembe v podatkih (Capelis in sod. 2000);

- neprimernost (neuporabnost) za politične odločitve (Capelis in sod. 2000);

- študije so pokazale, da so številne metode neprimerne za različne razmere (podobno bi lahko govorili za metodo ekoloških sledi) (The ecological footprint of Victoria 2005, 79). Kljub temu se je metoda ekoloških sledi s pomočjo uporabe standardov močno izboljšala (Ecological footprint standards 2006);

- izračun lahko vsako leto popravimo na osnovi novejših podatkov, možni so tudi majhni metodološki popravki;

- idealna metoda za sledenje območij z izrazito trajnostno sonaravnim razvojem in območij, kjer je trajnostno sonaravni razvoj naravnan nizko (ekološki primanjkljaj);

- metoda omogoča dobro primerjanje med državami, izračun trendov in napredka posameznih držav;

- kljub številnim drugim kompleksnih izračunom (npr. indeks humanega razvoja) je metoda ekološkega sledenja prinesla popolnejšo sliko trajnostno sonaravnega razvoja;

- idealni sintezni kazalec obremenjevanja in pritiskov na okolje;

- ekološko sledenje žal ne prikaže, kako intenzivna je raba prostora, izguba biodiverzitete, uničenje ekoloških storitev (npr. onesnaženje talne vode);

- ekološke sledi so idealno orodje in mehanizem za opozarjanje javnosti, institucij;

- najpomembnejše pri ekološkem sledenju je prav gotovo dejstvo, da se vrednotijo vse tri sfere sonaravno trajnostnega razvoja: ekonomska, socialna in okoljska (Wackernagel in sod. 2005);

- pri ekoloških sledeh gre za enoznačno vrednost, ki pa je zelo dobro predstavljiva tako na nacionalni kot na državni ravni;

- pri računanju ekoloških sledi za regije in lokalne skupnosti se še vedno uporablja komponentna metoda, ki pa je že nekoliko zastarela, čeprav tudi sodobna literatura še vedno govori o dveh tehnikah izračuna ekoloških sledi (komponentna metoda 'component method' in integralna metoda - 'compound method'; Wackernagel in sod. 2005). Po uvedbi standardov se je začela uporabljati metoda komparacije izračunanih nacionalnih ekoloških sledi. Metoda komparacije meri potrošnjo različnih dobrin na nivoju regij, mest in lokalnih skupnosti. Pri izboljšani metodi gre torej za prilagoditev izračunanih nacionalnih ekoloških sledi specifičnim lokalnim razmeram. Sami se za tak korak nismo odločili, saj se nam je zdelo smiselno, da za občino Ormož uporabimo že do sedaj uveljavljeno metodo.

Pojavita se dva temeljna problema vplivanja ekoloških sledi na vladno politiko:

- problem podatkov, saj manjše kot je območje, težje je dobiti podatke. Na lokalni ravni je tako dostopnih le nekaj podatkov;

- težavna primerljivost rezultatov, saj se uporabljajo različne metode in podatki. Kljub temu še vedno ni enotnega izračuna, kar kaže na potrebo po standardizaciji (Wiedmann in sod. 2006). 
V izračun ekoloških sledi ni mogoče vključiti naslednjih informacij (Switzerland's ecological footprint 2006, 40):

- ekoloških sledi ni mogoče gledati kot celosten indikator trajnostno sonaravnega razvoja;

- višina ekoloških sledi je prenizka (nekatere vsebine niso vključene);

- obnovljivi viri so slabo vračunani v ekoloških sledeh;

- nesonaravnih dejanj in velikih onesnaženj;

- velikih posegov človeka (na primer goloseki, pretirano ribištvo, onesnaževanje prsti in ozračja);

- izgub biološke diverzitete;

- obiskov turistov, ki povzročajo škodo okolju.

\section{SKLEP}

Sedanji način življenja razvitega sveta je razsipen, raba energije velika in uničevanje ekosistemov veliko. Ekološke sledi predstavljajo pomemben podatek pri proučevanju okolja in pritiskov. Pri opredeljevanju geografskih zasnov za pripravo LPVO lahko ekološke sledi pomenijo pomemben podatek, saj z njihovo pomočjo analiziramo pritiske okolja kot celoto, ter hkrati na osnovi podatka podamo usmeritve zmanjšanja pritiskov (ekoloških sledi).

$\mathrm{V}$ članku smo s pomočjo komponentne metode izračunali ekološke sledi in potrebno bioproduktivno površino za območje občine Ormož. Potrebno je poudariti, da je dostop do metode težaven, saj so snovalci metode za javnost zaprli vse informacije v zvezi s podrobnostmi metode računanja ekoloških sledi. Ekološke sledi predstavljajo kazalec, ki nam pokaže, ali proučevano območje živi v skladu s trajnostno sonaravnimi smernicami. Podatek je uporaben, saj se lahko z rezultatom izračuna ekoloških sledi veliko lažje podajo geografske zasnove za LPVO. Ugotovili smo, da je metoda merjenja trajnostno sonaravnega načina življenja s pomočjo ekoloških sledi najprimernejša sintezna okoljska metoda za lokalno skupnost, kot je občina Ormož.

Obremenitve prebivalcev občine Ormož so nekaj nad zmožnostmi narave. Izračun ekoloških sledi je pokazal, da občina Ormož zelo obremenjuje okolje, in da način življenja lokalnega prebivalstva in pritiski na okolje povzročajo obremenitve, ki so večje kot znaša absorbcijska in nevtralizacijska sposobnost okolja. Govorimo o okoljski neuravnoteženosti občine oziroma načina organizacije materialnega življenja, dejavnosti.

Problem metode so vhodni podatki, ki jih je za manjša območja premalo, tako da je potrebno nekatere podatke prenesti iz večjih prostorskih enot. Menimo, da so vrednosti ekoloških sledi podcenjene, saj v metodologiji še niso vključeni vsi pritiski, ki jih družba povzroča. Metoda se še razvija in se vsakodnevno posodablja. Postopek izračuna ekoloških sledi je predvsem zaradi teženj po trženju metode $\mathrm{v}$ zadnjih letih postal za javnost onemogočen in tajen. Metoda ekoloških sledi je pomembno orodje in predstavlja eno glavnih geografskih zasnov za pripravo LPVO občine Ormož. Metoda je v slovenskem prostoru zelo malo uporabljena.

Za občino Ormož nam je rezultat pokazal, da le-ta ni na poti trajnostno sonaravnega razvoja, kar smo želeli tudi dokazati. Pritiski na okolje so nad naravno absorpcijsko sposob- 
nostjo narave. Ekološke sledi so namreč večje od slovenskega in svetovnega povprečja. Ekološka neuravnoteženost znaša 1,11 gha/preb. Ob sedanji porabi in načinu življenja bi potrebovali 1,3 sedanjih površin Zemlje, če bi celotna svetovna populacija živela tako kot živijo občani občine Ormož.

\section{Viri in literatura}

Calculating the ecological footprint of ICLEI Cities. Global Footprint Network. Oakland 2006.

Capelis, S., Capelilis L., Friedenburg, M., Juniper, I,. Juniper, S., Kirchoff, G., Lysell, H., Lysell, M. 2000: Sustainable Sanoma Country. Graton GraphX. Sebastopol.

Carbon footprint. Global Footprint Network. Oakland.

Chambers, N., Simmons C., Wackernagel M. 2000: Sharing natures interest. Ecological footprints as an indicator of sustainability. Earthscan. London.

City limits. IWM (EB) Chartered Institution of Wastes Management Environmental Body. London 2002.

Ecological footprint standards. WWF International, Global Footprint Network. Gland, Oakland 2006.

Global Footprint Network. 2006. Medmrežje: http://www.footprintnetwork.org (15.12. 2006).

Kooten, C. van, Bulte, E. H. 2000: The economics of nature. Managing biological assets. Blackwell. Malden (Mass.). Oxford.

Lah, A. 2002: Prometni sistem v prenovi. V: Promet in okolje. Zbirka Usklajeno in sonaravno 7, 8-12. Svet za varstvo okolja RS. Ljubljana.

Living planet report 2004. A Banson Production. Cambridge 2004.

Living planet report 2005. A Banson Production. Cambridge 2005.

Living planet report 2006. A Banson Production. Cambridge 2006.

Matijašič, D. 2003: Uporaba metode stalnih vzorčnih ploskev na ZGS. Oddelek za gozdnogospodarsko načrtovanje. Zavod za gozdove Slovenije. Ljubljana.

Medved, S. 2006: Present an future ecological footprint of Slovenia. The influence of energy demand scenarios. Ecological modelling 192, 1-2, 25-36. Amsterdam.

Statistični letopis Republike Slovenije 1996. Statistični urad RS. Ljubljana 1997.

Statistični letopis Republike Slovenije 2002. Statistični urad RS. Ljubljana 2003.

Statistični letopis Republike Slovenije 2004. CD-ROM, Statistični urad RS. Ljubljana 2005. Statistični letopis Republike Slovenije 2006. CD-ROM, Statistični urad RS. Ljubljana 2007.

Switzerland's ecological footprint. Federal Statistical Office. Neuchâtel 2006. Medmrežje: http://www.bfs.admin.ch/bfs/portal/en/index/themen/21/03/blank/blank/01.html (31.12.2007).

Šašek-Divjak, M. 1997: Trajnostno uravnotežen razvoj mest. Doktorska disertacija. Fakulteta za arhitekturo. Ljubljana.

The ecological footprint of Victoria. EPA Victoria, Global Footprint Network 91. Sydney 2005.

The footprint of Wales. WWF-UK, Welsh Assembly Government. Cardiff 2002. 
Vendramin, M. 2005: Okoljski odtis. Ekonomsko ogledalo 11, 8-9, 20-21. Ljubljana.

Vintar Mally, K. 2006: Okoljevarstvena in socialnoekonomska protislovja držav v razvoju. Doktorska disertacija. Oddelek za geografijo, Filozofska fakulteta. Ljubljana.

Wackernagel, H., Smith, K., Banzhaf, S., H., Walsh, R. 2004: Estimating the general equilibrium benefits of large changes in spatilly delineated public goods. International economic rewiew 45, 4, 1047-1076. Philadelphia.

Wackernagel, M., Monfreda, C., Moran, D., Wermer P., Goldfinger, S., Deumling, D., Murray, M. 2005: National footprint and biocapacity accounts 2005: The underlying calculation method. Global Footprint Network. Oakland.

Wackernagel, M., Rees, W. E. 1996: Our ecological footprint. Reducing human impact on the Earth, New Society Publishers. Gabriola Island.

Wiedmann, T., Minx, J., Barrett, J., Wackernagel, M. 2005: Allocating ecological footprints to final consumption categories with input-output analysis. Ecological economics 56, 1, 28-48. Amsterdam.

Žun, Š. 2004: Ekološko sledenje razvoja lokalnih skupnosti. Magistrsko delo, Fakulteta za strojništvo. Ljubljana.

\section{ECOLOGICAL FOOTPRINTS AS IMPORTANT ELEMENT OF GEOGRAPHICAL CONCEPTS FOR THE PREPARATION OF THE LOCAL ENVIRONMENTAL ACTION PLAN}

\section{Summary}

Present style of modern world life is lavish, use of energy and damaging of ecosystems high. Ecological footprints can serve as the important information to research environment and ecological pressures. To define geographical concepts for the preparation of the local environmental action plan, we can use ecological footprints as important information. Such information can help us to analyze pressures to the environment and, at the same time, to give us directions for the decreasing pressures (ecological footprints).

With the help of component method we have calculated ecological footprints and bioproductive area of Ormož municipality. The access to the method is very difficult, because the authors have closed all information how to calculate ecological footprints. Ecological footprints show if the area under investigation live according to the sustainable guidelines. With the help of ecological footprints we can easier establish geographical concepts for the preparation of the local environmental action plan. We found out that the method of ecological footprints is one of the best methods of measuring sustainable lifestyle of a local community, as is Ormož municipality.

Pressures of inhabitants in the Ormož municipality are something above nature capacity. Calculation of ecological footprints has shown us that the load on the environment in Ormož municipality is high. The lifestyle of local population and pressures are larger as nature's capacity.

The main problem was that we had only few information available for our local region. Therefore, we had to calculate some values from the averages for the entire Slovenia. We 
think that the calculated ecological footprints are undervalued, because all the pressures are not included into the methodology. The method is still under development and is daily modernizing. The process of calculating ecological footprints has become unavailable for the public, first because of the marketing. The method of ecological footprint is important tool and it represents one of the main geographical concepts for the preparation of the local environmental action plan for Ormož municipality. Until now, the method was little used in Slovenia.

The calculated ecological footprints have shown that Ormož municipality is not on way of sustainable development. Pressures on environment are exceeding the nature's absorption ability. Ecological footprints are larger as in Slovene and in the world average. Ecological footprints are unbalanced and amounted 1.11 gha per inhabitant. At present, according to the way of consumption and to the lifestyle we would need up to 1.3 times of present area of the Earth, if all the Earth's population would live as do the inhabitants of Ormož municipality. 